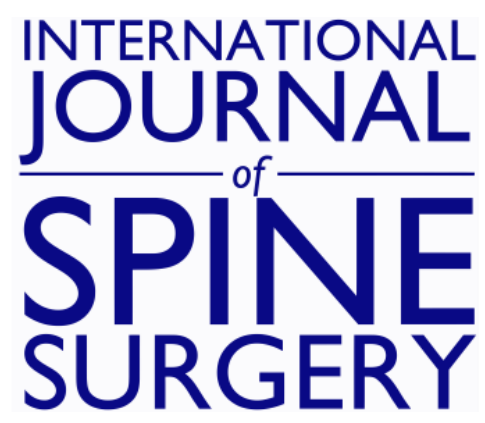

\title{
A Novel Intraoperative Technique to Determine Cranio-Caudal Angulation of Pedicle Screws in Thoracolumbar Spine: A Prospective Computerized Tomography-Based Analysis of 428 Screws
}

NIRMAL D. PATIL and ADITYA DAHAPUTE

Int J Spine Surg 2020, 14 (5) 722-730

doi: https://doi.org/10.14444/7104

http://ijssurgery.com/content/14/5/722

This information is current as of April 25, 2023.

Email Alerts Receive free email-alerts when new articles cite this article. Sign up at:

http://ijssurgery.com/alerts 


\title{
A Novel Intraoperative Technique to Determine Cranio- Caudal Angulation of Pedicle Screws in Thoracolumbar Spine: A Prospective Computerized Tomography-Based Analysis of 428 Screws
}

\author{
NIRMAL D. PATIL, MBBS, MS (ORTHO), MRCS (ENG), DNB (ORTHO), MNAMS, INTERNATIONAL \\ ORTHOPEDIC DIPLOMA (SICOT, Belgium), ${ }^{1}$ ADITYA DAHAPUTE, MBBS, MS (ORTHO), MRCS (ENG), \\ DNB (ORTHO), MNAMS ${ }^{2}$ \\ ${ }^{I}$ Department of Spine surgery, Queens Medical Centre, Nottingham, UK, ${ }^{2}$ Seth Gordhandas Sunderdas Medical College and King Edward Memorial Hospital, \\ Parel, Mumbai, India
}

\begin{abstract}
Background: We report a novel technique of directing the sagittal profile of thoracic and lumbar pedicle screws using a freehand technique without the use of intraoperative monitoring.

Methods: This is a prospective computerized tomography (CT)-based evaluation of pedicle screw insertion in the thoracic and lumbar spine of 64 patients operated upon for varied etiologies. All the patients were operated upon independently by 2 young surgeons with 1 year of spinal-fellowship experience. Intraoperatively, a right-angle retractor was positioned to determine the sagittal inclination of the pedicle screw. Postoperatively, sagittal CT scans were analyzed for the sagittal profile of the screw. The vertebral bodies were divided into 3 equidistant zones (A, B, and C) from the superior to inferior endplates, and the positions of the screw tips were noted.

Results: There were 41 men and 23 women (mean age $=45.5$ years). A total of 428 screws were inserted. There were 2 cases of superior pedicle wall violation in D1 and D5. The majority $(96.97 \%)$ of the pedicle screws were inserted into zones $\mathrm{A}$ and $\mathrm{B}$.

Conclusions: We introduced a simple, accurate, and safe method of directing the sagittal inclination of the pedicle screw in the thoracic and lumbar spine without intraoperative image guidance.
\end{abstract}

Lumbar Spine

Keywords: pedicle, screw, thoracic, lumbar, spine, application, insertion, freehand, sagittal

\section{INTRODUCTION}

Optimal pedicle screw placement is a critical issue due to the unique neurologic and vascular anatomy present in proximity to the pedicle. ${ }^{1,2}$ The freehand technique of pedicle screw placement was found to be an accurate and safe method for a variety of spinal disorders, including spinal deformities. ${ }^{2-4}$ Lateral radiograph and intraoperative fluoroscopy are often used by spine surgeons to assess the cranio-caudal inclination of pedicle screw placement. However, the sagittal profile of the patient can change from the supine position (position for obtaining a radiograph and $\mathrm{CT}$ ) to the prone (intraoperative), during any intraoperative manipulation, and it also varies with the amount of hip flexion. In the upper thoracic spine, obtaining a proper lateral view with fluoroscopy is difficult due to the superimposition of the shoulder. ${ }^{5}$ Furthermore, in patients with vertebral body fracture, there is significant kyphosis in the proximal vertebral levels that will alter the sagittal angulation of screws. For accurate pedicle screw placement, many image-guided technologies have been developed; however, its cost-effectiveness is debatable. ${ }^{6}$ There are a few studies that have addressed assessing the sagittal-plane orientation of the pedicle screw. ${ }^{5,7-12}$ The previously published methods of determining the sagittal angulation of a pedicle screw in vivo can only provide a vague visual cue to the surgeon, which will result in human errors. ${ }^{5,7-12}$ It is known that even experienced spine surgeons cannot aim for a predefined angulation. ${ }^{13}$ The human eye can identify orthogonal angles more accurately; therefore, when a reference frame is added, the accuracy of execution of the screw can increase. ${ }^{14}$ 

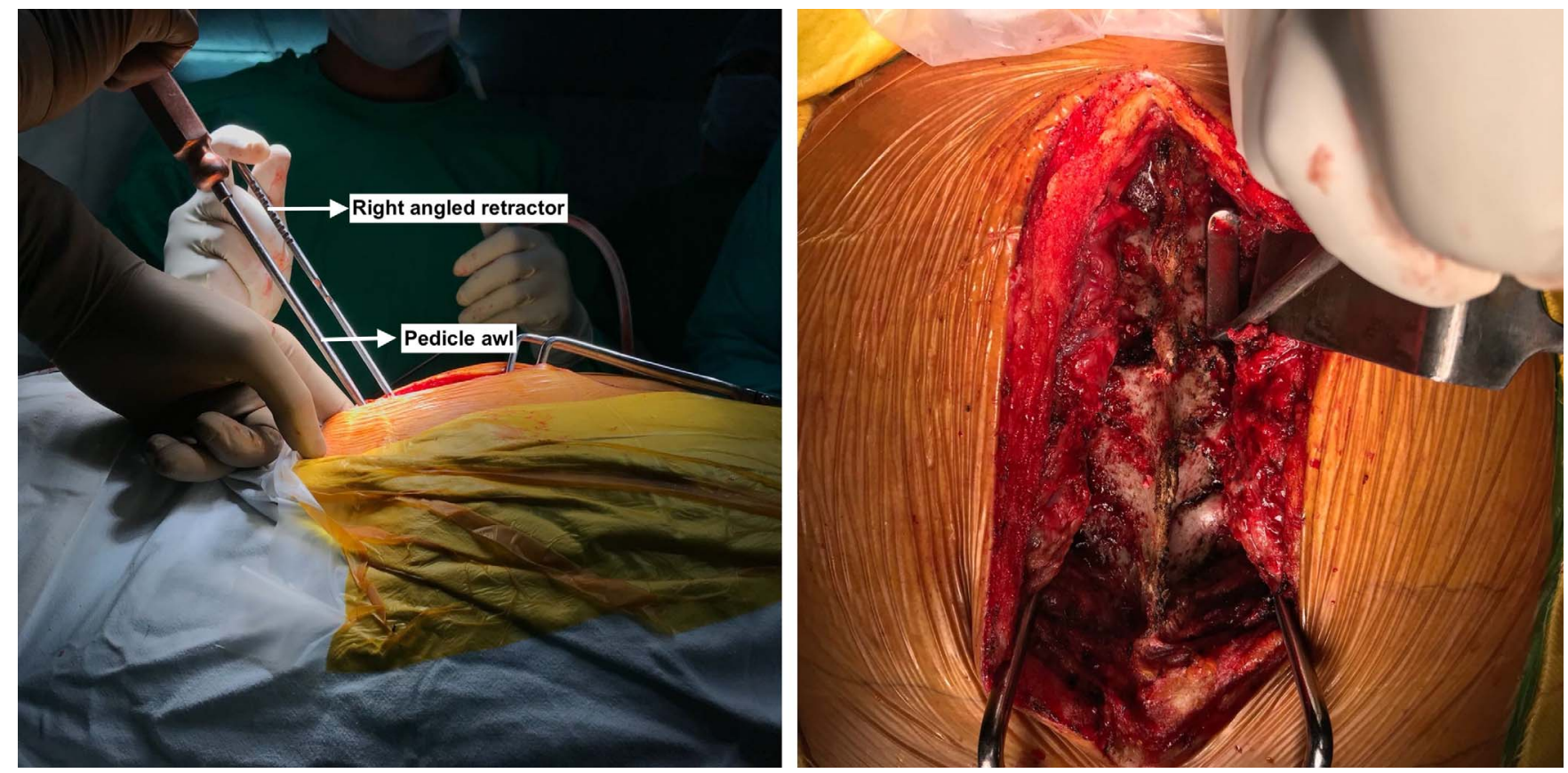

Figure 1. Intraoperative image showing the side and end-on view of placement of the right angled retractor.

The first author (NDP) has published the relation between the interlaminar line and pedicle axis in the thoracic, and lumbar spine. We noted that the interlaminar line was nearly perpendicular (pedicle interlaminar angle in the dorsal spine: mean $=$ $88.41^{\circ}$; and in the lumbar spine: mean $=90.87^{\circ}$ ) to the axis of the pedicle screw insertion and was independent of the sagittal profile of the spine. ${ }^{15,16}$ Applying this principle, we placed the short limb of a right-angled retractor flush upon the posterior aspect of the inferior edge of the lamina to be screwed and the one above it to determine the orientation of the screw. In the present study, we have analyzed the efficacy of predicting the sagittal profile of a pedicle screw using this simple technique without the use of intraoperative imaging or navigation. There are no in vivo studies dedicated to the intraoperative estimation of the cranio-caudal angulation of a pedicle screw without fluoroscopic guidance, to our knowledge. We have not analyzed the medio-lateral inclination and medio-lateral pedicle wall breaches in this study.

\section{MATERIALS AND METHODS}

Following institutional review board approval, the authors performed a prospective radiographic and computerized tomography (CT) review of pedicle screws inserted from T1-L5 in 64 consecutive patients who were treated at our institute (Seth
Gordhandas Sunderdas Medical College and King Edward Memorial Hospital) with open posterior spinal fusion and instrumentation from July 2018 to March 2019. Informed consent was obtained from all individual participants included in the study. All the cases were operated independently by 2 young surgeons with 1 year of spinal-fellowship experience. Patients below 18 years of age were excluded from this study, as were patients who had scoliosis, revision surgeries, laminectomy defects, and/or lytic spondylolisthesis. A standard posterior exposure was performed. The screw entry point was the same as described by Kim et $\mathrm{al}^{2}$ for different spinal levels. The medio-lateral inclination was determined by studying the preoperative CT scans. The sagittal profile of the pedicle screws was determined by placing a right-angle retractor over the contralateral posterior aspect of the edges of the lamina to be screwed and the one above it. The inclination of the long limb of the right angled retractor was followed during insertion of the pedicle screws in the lumbar spine, whereas in the dorsal spine the screw was directed $5^{\circ}$ caudal using a goniometer (Figures 1 and 2). The pedicle was cannulated with a pedicle gearshift probe to a proper depth. The path was confirmed with a ball-tipped flexible probe, following which a pedicle screw was inserted. All pedicle screws were inserted by the freehand method. No intraoperative imaging or navigation was used. 


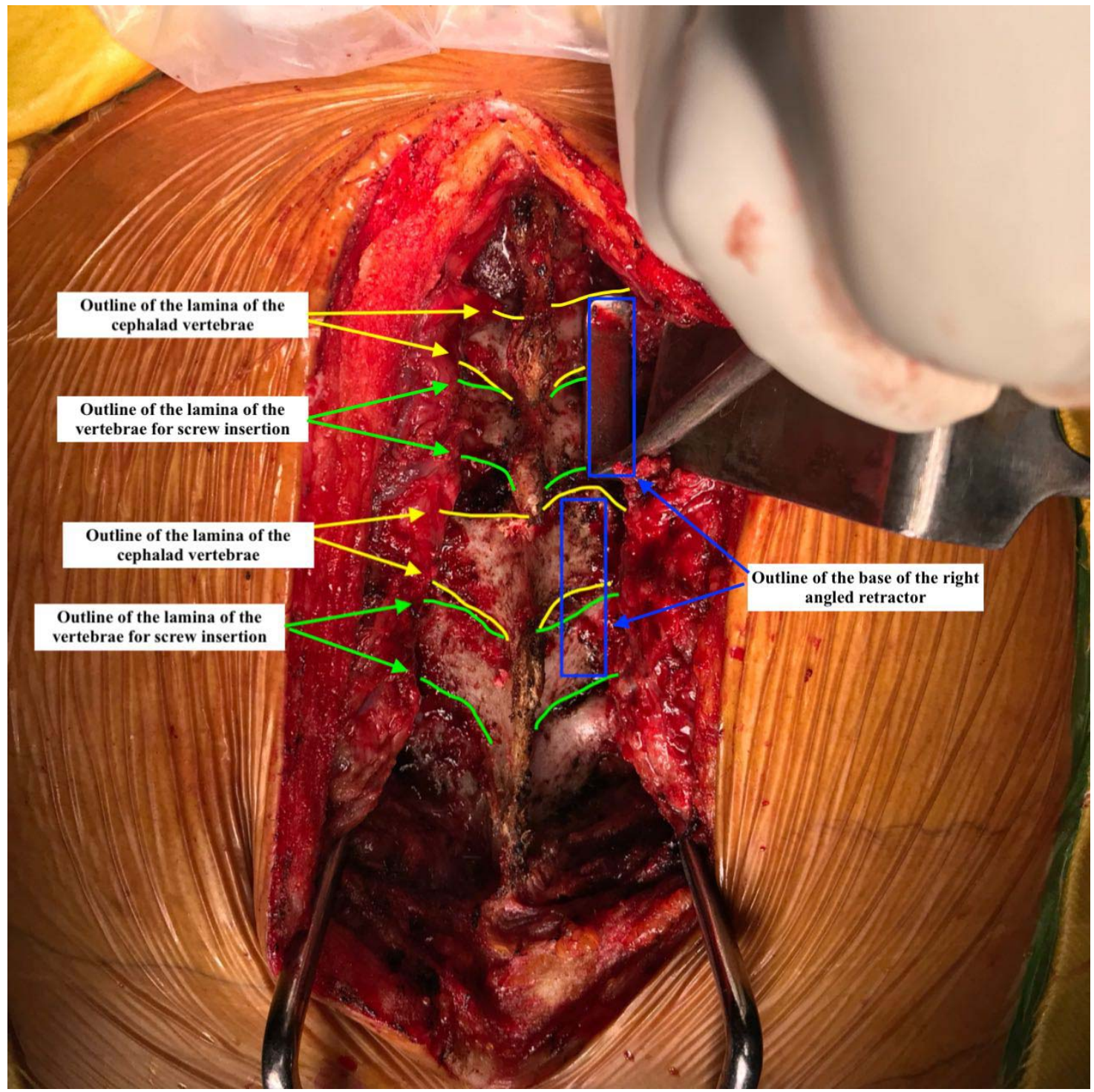

Figure 2. Intraoperative image showing the outline of the lamina of the cephalad vertebrae and the vertebrae for screw insertion. A rectangular box is the outline for the base of the right-angled retractor. This must be placed on the surface of adjacent lamina on the contralateral side. The long limb of the retractor then guides the sagittal angulation of the screw.

Postoperatively, CT scans with 2-mm cuts were used to assess the positioning of the pedicle screw tips within the vertebral bodies. If only short pedicle screws were inserted in the fractured vertebral body,

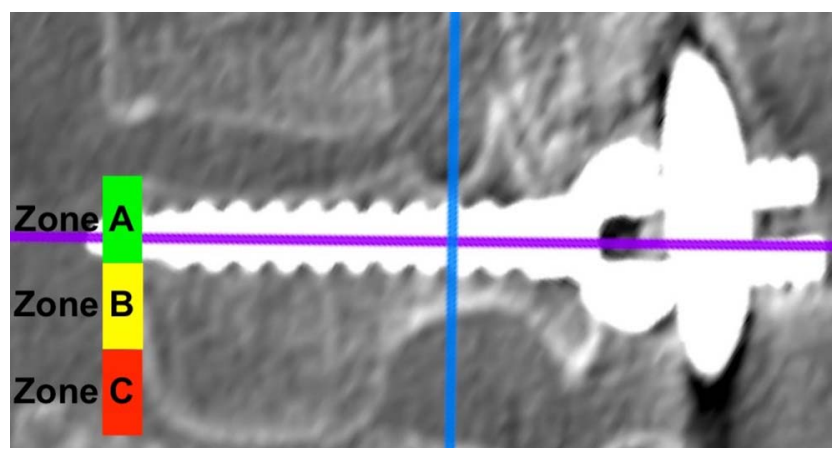

Figure 3. The 3 zones of the exit of the screws. the screw axis was extrapolated to reach the anterior cortex of the vertebral body (simulating the final position of the pedicle screw tips if they had been fully inserted). A sagittal cut along the pedicle axis was constructed using the 3D MPR Reconstruction mode of the Horos software (version 3.3.5; Horos Project, USA). The vertebral bodies were divided from the superior to the inferior endplate into 3 equidistant zones that were designated as $\mathrm{A}, \mathrm{B}$, and C (Figure 3). Screws were categorized as safe when they were in zones A and B in the sagittal cuts of the CT scans (Figures 4 and 5). The scans were also analyzed for perforation of the pedicle walls or violation of the superior or inferior disc spaces. All of the measurements were performed using Horos 

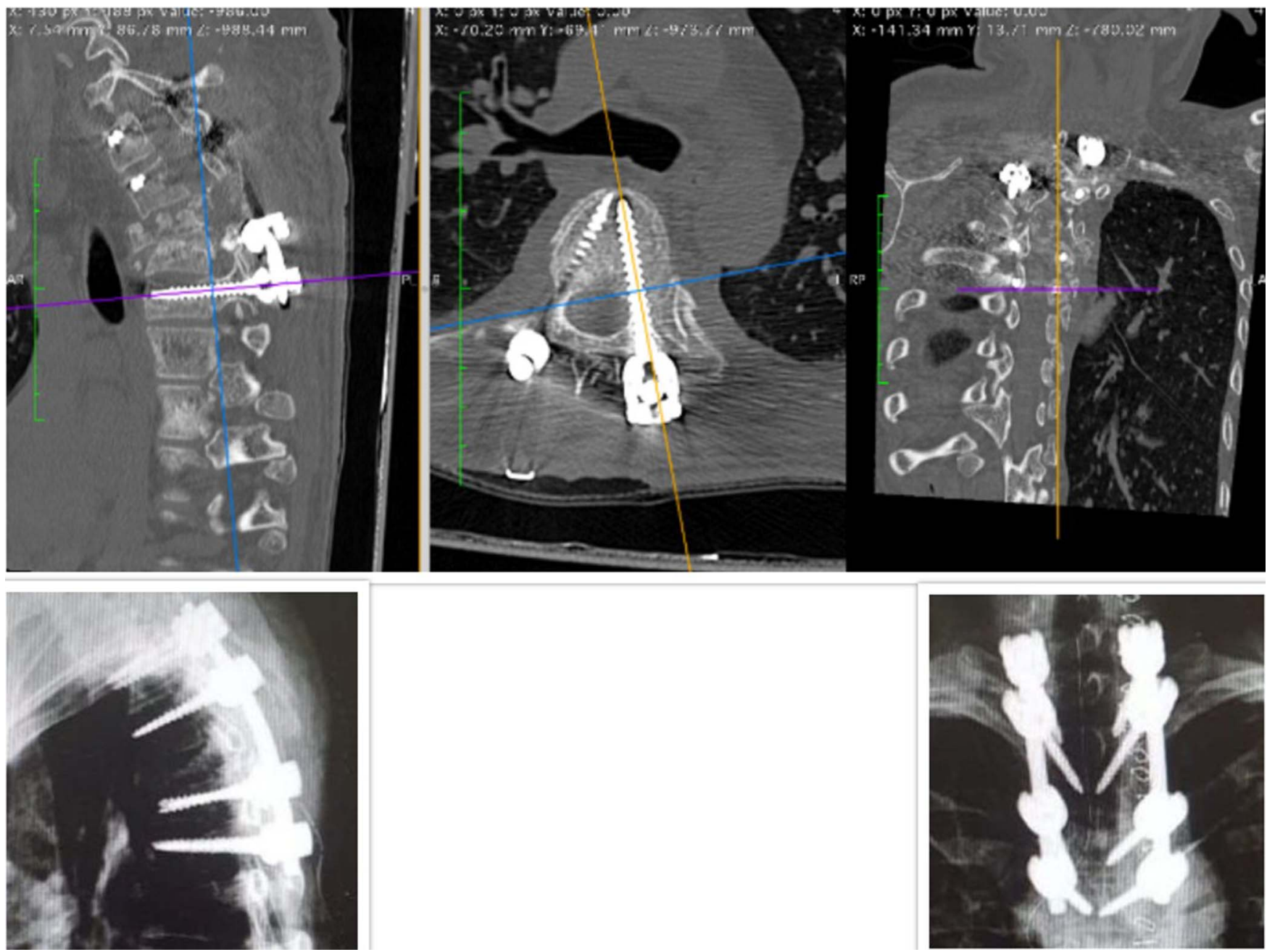

Figure 4. Case of neglected old D3 vertebral body fracture treated with posterior spinal fusion and instrumentation from D1 to D5. Image shows the 3D MPR mode of Horos with cuts.

software (version 3.3.5). Assessments were performed twice by each author. Statistical analysis was performed with use of SPSS (version 19) software (IBM Corp, Armonk, NY).

\section{RESULTS}

There were 41 men $(64 \%)$ and 23 women $(35.93 \%)$, with a mean age of 45.5 years \pm 5.3 years (18 to 70 years). There were 40 cases of fracture, 15 cases of degenerative spine, and 9 cases of spondylitis (Table 1). A total of 428 screws were inserted. Of those, 88 screws were in the upper thoracic spine, 102 in the middle thoracic, 72 in lower thoracic, and 166 in the lumbar spine (Table 2). Of all pedicle screws, $96.97 \%$ were in the upper two thirds of the vertebral body (zones A and B; Table 3). The percentage of pedicle screws in the safe zone increased from $90.9 \%$ in the upper thoracic spine to $100 \%$ in the low thoracic and lumbar spine. There were 2 cases of screw cut out of the superior pedicle wall (1 each at D1 and D5; Figure 6). Both the cases were grade 1 breach as per Kim et al. $^{2}$ However, intraoperatively we did not notice any breach of the superior and inferior pedicle wall. There was good correlation between the 2 observers for analysis of the zones and screw cutouts $(r=0.85)$. Any differences between the 2 observers regarding the gradings were solved by revisiting the images and mutually deciding upon the grade. There was no statistical difference between the zone of exit of the screw and age $(P=$ .19), sex $(P=.17)$, diagnosis $(P=.09)$, or side $(P=$ .2).

\section{DISCUSSION}

The human eye often underestimates or overestimates the angle when the point of view is not orthogonal. ${ }^{14}$ Inserting a screw parallel to a 

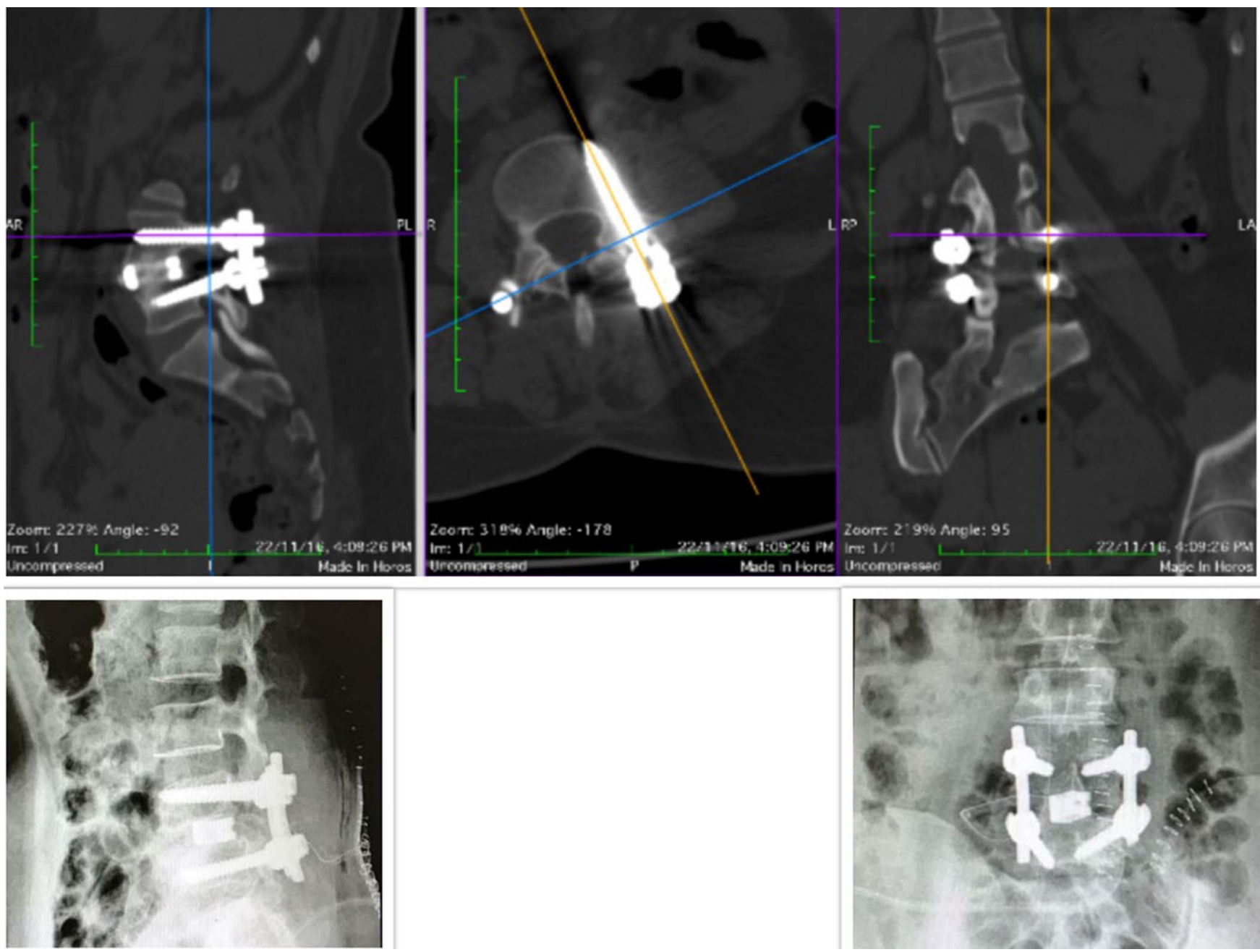

Figure 5. L4-L5 transforaminal lumbar interbody fusion performed for a case of degenerative disc disease. The computed tomography scan shows the reconstructed postoperative images with the screw in zone A. The postoperative radiograph of the same patient is represented in Figure 7.

reference frame is therefore more accurate than inserting it at a predefined angle. This is especially true for young spine surgeons. The sagittal trajectory of the pedicle screws in the upper thoracic spine and in lordotic or kyphotic spine deformity (due to vertebral body fracture, spondylitis, or any other reasons) can be difficult to determine because the screws do not lie in the orthogonal reference frame of the eye (Figure 7). It is difficult and cumbersome to orient one's vision parallel or perpendicular to this deformity to direct the screws, which can result

Table 1. Diagnosis.

\begin{tabular}{lccr}
\hline & \multicolumn{2}{c}{ No. of Patients } & \\
\cline { 2 - 3 } Diagnosis & Thoracic & Lumbar & Total \\
\hline Fracture & 20 & 20 & 40 \\
Spondylitis & 7 & 2 & 9 \\
Degenerative & 6 & 9 & 15 \\
Total & 33 & 31 & 64 \\
\hline
\end{tabular}

Table 2. Screws per level.

\begin{tabular}{lccc}
\hline & \multicolumn{2}{c}{ No. of Screws } & \\
\cline { 2 - 3 } Levels & Right & Left & Total \\
\hline D1 & 9 & 9 & 18 \\
D2 & 9 & 9 & 18 \\
D3 & 11 & 11 & 22 \\
D4 & 15 & 15 & 30 \\
D5 & 15 & 15 & 30 \\
D6 & 12 & 12 & 24 \\
D7 & 11 & 7 & 22 \\
D8 & 7 & 6 & 14 \\
D9 & 6 & 8 & 12 \\
D10 & 8 & 14 & 16 \\
D11 & 14 & 14 & 28 \\
D12 & 14 & 16 & 28 \\
L1 & 16 & 15 & 32 \\
L2 & 15 & 11 & 30 \\
L3 & 11 & 20 & 22 \\
L4 & 20 & 21 & 40 \\
L5 & 21 & & 42 \\
Total & & & \\
\hline
\end{tabular}


Table 3. Zone of exit.

\begin{tabular}{|c|c|c|c|c|}
\hline \multirow[b]{2}{*}{ Levels } & \multicolumn{3}{|c|}{ Zones of Exit } & \multirow[b]{2}{*}{ Total } \\
\hline & $\mathbf{A}$ & B & C & \\
\hline \multicolumn{5}{|l|}{ High thoracic (right) } \\
\hline D1 & 4 & 3 & 2 & 9 \\
\hline D2 & 4 & 4 & 1 & 9 \\
\hline D3 & 5 & 5 & 1 & 11 \\
\hline D4 & 9 & 6 & 0 & 15 \\
\hline Total & 22 & 18 & 4 & 44 \\
\hline Percentage & 50 & 40.9 & 9.1 & 100 \\
\hline \multicolumn{5}{|l|}{ High thoracic (left) } \\
\hline D1 & 4 & 4 & 1 & 9 \\
\hline D2 & 4 & 4 & 1 & 9 \\
\hline D3 & 5 & 4 & 2 & 11 \\
\hline D4 & 8 & 7 & 0 & 15 \\
\hline Total & 21 & 19 & 4 & 44 \\
\hline Percentage & 47.77 & 43.18 & 9.9 & 100 \\
\hline \multicolumn{5}{|l|}{ Midthoracic (right) } \\
\hline D5 & 8 & 6 & 1 & 15 \\
\hline D6 & 7 & 4 & 1 & 12 \\
\hline D7 & 6 & 5 & 0 & 11 \\
\hline D8 & 4 & 3 & 0 & 7 \\
\hline D9 & 4 & 2 & 0 & 6 \\
\hline Total & 29 & 20 & 2 & 51 \\
\hline Percentage & 56.86 & 39.21 & 3.92 & 100 \\
\hline \multicolumn{5}{|l|}{ Midthoracic (left) } \\
\hline D5 & 8 & 5 & 2 & 15 \\
\hline D6 & 7 & 4 & 1 & 12 \\
\hline D7 & 7 & 4 & 0 & 11 \\
\hline D8 & 5 & 2 & 0 & 7 \\
\hline D9 & 5 & 1 & 0 & 6 \\
\hline Total & 32 & 16 & 3 & 51 \\
\hline Percentage & 62.74 & 31.37 & 5.8 & 100 \\
\hline \multicolumn{5}{|l|}{ Low thoracic (right) } \\
\hline D10 & 5 & 3 & 0 & 8 \\
\hline D11 & 9 & 5 & 0 & 14 \\
\hline D12 & 10 & 4 & 0 & 14 \\
\hline Total & 24 & 12 & 0 & 36 \\
\hline Percentage & 66.6 & 33.34 & 0 & 100 \\
\hline \multicolumn{5}{|l|}{ Low thoracic (left) } \\
\hline D10 & 5 & 3 & 0 & 8 \\
\hline D11 & 9 & 5 & 0 & 14 \\
\hline D12 & 10 & 4 & 0 & 14 \\
\hline Total & 24 & 12 & 0 & 36 \\
\hline Percentage & 66.6 & 33.34 & 0 & 100 \\
\hline \multicolumn{5}{|l|}{ Lumbar (right) } \\
\hline $\mathrm{L} 1$ & 12 & 4 & 0 & 16 \\
\hline $\mathrm{L} 2$ & 10 & 5 & 0 & 15 \\
\hline L3 & 8 & 3 & 0 & 11 \\
\hline $\mathrm{L} 4$ & 13 & 7 & 0 & 20 \\
\hline L5 & 15 & 6 & 0 & 21 \\
\hline Total & 58 & 25 & 0 & 83 \\
\hline Percentage & 69.87 & 30.12 & 0 & 100 \\
\hline \multicolumn{5}{|l|}{ Lumbar (Left) } \\
\hline $\mathrm{L} 1$ & 13 & 3 & 0 & 16 \\
\hline $\mathrm{L} 2$ & 11 & 4 & 0 & 15 \\
\hline L3 & 8 & 3 & 0 & 11 \\
\hline L4 & 14 & 6 & 0 & 20 \\
\hline L5 & 14 & 7 & 0 & 21 \\
\hline Total & 60 & 23 & 0 & 83 \\
\hline Percentage & 72.2 & 27.7 & 0 & 100 \\
\hline All levels, right total & 133 & 75 & 6 & 214 \\
\hline All levels, right \% & 62.14 & 35.04 & 2.8 & 214 \\
\hline All levels, left total & 137 & 70 & 7 & 214 \\
\hline All levels, left \% & 64.01 & 32.71 & 3.2 & 100 \\
\hline All levels, total \% & 63.08 & 33.87 & 3.03 & 100 \\
\hline
\end{tabular}

in misplacement of screws. Using the right-angle retractor technique will greatly increase the accuracy of pedicle screw insertion by young spine surgeons. Applying this principle of orthogonal reference frame, the first author (N.D.P.) described a technique to determine the version of the femur in patients with destroyed anatomical landmarks. ${ }^{17}$

There are several methods of pedicle screw insertion to enhance safety and decrease complications: intraoperative fluoroscopy, computer-guided navigation systems, and intraosseous endoscopy. $3,18,19$ Although computer-assisted image guidance has been shown to significantly decrease the cortical violation rate, this method can increase the screw insertion time by as much as $50 \%$ at each level. ${ }^{20}$ Also, the patient position may change during surgery, increasing the risk of registration error with navigation. ${ }^{21}$ These systems are expensive, involve a significant learning curve, and are not widely available. This is true especially in developing countries. Spine surgeons typically use fluoroscopy as a lateral view to determine the sagittal orientation of the screw. Use of fluoroscopy results in significant radiation exposure to the surgeon's hands and to the patients. Rampersaud et $\mathrm{al}^{22}$ found that the average fluoroscopy exposure time for spine surgeons was 9.3 seconds per screw, and the spine surgeon's hands are exposed to 10 times the radiation dose as compared with other musculoskeletal procedures. These figures can be even higher for younger surgeons who take longer to insert a screw. A single scoliosis surgery exposes the surgeons to around $13.49 \mathrm{mSv}$ of whole-body ionizing radiation, which exceeds the recommended limits of $10 \mathrm{mSv}$ per year of life. At this rate, a novice spine surgeon would exceed the lifetime limit in less than 10 years. ${ }^{23}$ Use of the long arm of the right-angled instrument for sagittal orientation of the screw in spinal surgeries will provide younger surgeons with an accurate and easy technique that will eliminate the need for continuous fluoroscopic monitoring for screw insertion.

The incidence of cranio-caudal pedicle wall breaches reported in the literature ${ }^{20,24,25}$ range from $1.6 \%$ to $25.1 \%$. Although they are not as serious as the medio-lateral breaches, they decrease the strength of the construct. ${ }^{26}$ The inferior wall breach can cause nerve palsies. ${ }^{1}$ There are only a few studies on sagittal trajectories of the screw. Fennel et $\mathrm{al}^{12}$ suggested that a screw must be inserted orthogonal to the dorsal curvature of the spine. 

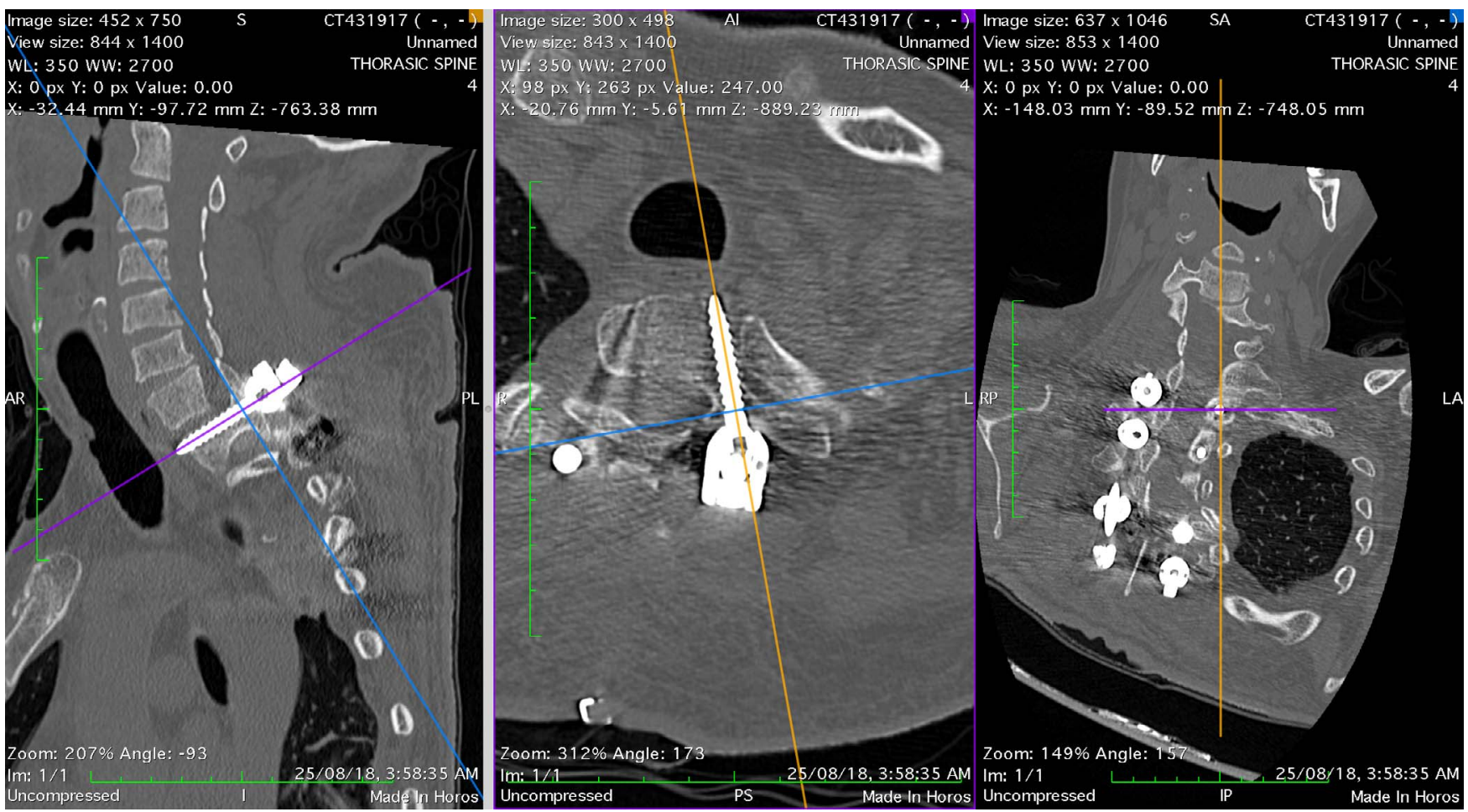

Figure 6. A sagittal cut along the axis of the screw showing a grade 1 breach of the superior pedicle wall.

However, this is vague and does not give a definite angle for screw insertion. Rivkin et $\mathrm{al}^{8}$ reported that the sagittal trajectory is perpendicular to the long axis of the lamina. However, it is difficult to decipher the long axis of the lamina because it can be hidden under the inferior facet of the cephalad vertebrae. Parker et $\mathrm{al}^{7}$ used the superior endplate as a guide for sagittal trajectory of the screw. This can only be possible with the use of intraoperative fluoroscopy, which is difficult in the cervicothoracic region. ${ }^{7} \mathrm{Li}$ et $\mathrm{al}^{11}$ proposed that a pedicle screw be inserted perpendicular to the supraspinal ligament, which is a soft tissue structure and hence can be easily deformable.

The senior author (K.D.L) of a CT-based study ${ }^{15,16}$ for analyzing the relation between inter- laminar line and pedicle axis often used the rightangle instrument to direct the screws craniocaudally in scoliosis patients. We believe this method can be applied to the entire spine. In this study, we found that the interlaminar line is $86^{\circ}$ in relation to the pedicle axis in the upper dorsal spine (D1 to D6) and almost $90^{\circ}$ (range, $88^{\circ}$ to $94^{\circ}$ ) in the lower dorsal and lumbar spine. ${ }^{16}$ Kim et al ${ }^{2}$ has revived interest among the spine surgeons to use the freehand technique. The use of a right-angle interlaminar technique for the sagittal trajectory in addition to a gearshift probe for the medio-lateral trajectory will increase the safety of a young surgeon cannulating the pedicle without the need for intraoperative monitoring.
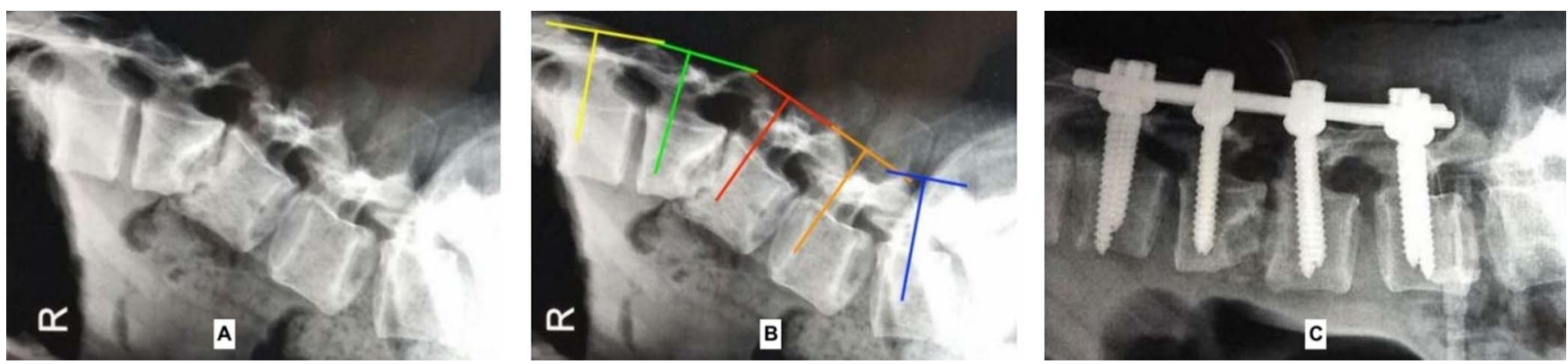

Figure 7. (A) L2-L3 spondylodiscitis. (B) Interlaminar line and a line drawn perpendicular to the interlaminar line passing through the base of the superior articular facet simulating the base of the right angle). (C) Final postoperative x-ray. 
The limitation of this technique is that it can only be used in open spine surgery. It also cannot be used in laminectomy defect positions. We have studied the use of this technique in fracture degenerative and spondylitis patients. Further prospective in vivo and CT-based studies are required to understand whether this technique can be used in scoliosis patients as well.

\section{CONCLUSIONS}

We have introduced a reliable and safe method for directing the sagittal inclination of pedicle screw placement in the thoracic and lumbar spine. Our freehand technique using a right-angled retractor is a simple method using a common tool in spine surgery. This technique will limit the usage of intraoperative fluoroscopy and decrease craniocaudal pedicle wall breaches.

\section{REFERENCES}

1. Ebraheim NA, Jabaly G, Xu R. Anatomic relations of the thoracic pedicle to the adjacent neural structures. Spine. 1997;22(14):1553-1557.

2. Kim YJ, Lenke LG, Bridwell KH. Free hand pedicle screw placement in the thoracic spine: is it safe? Spine. 2004;29(3):333-342.

3. Agarwal A, Chauhan V, Singh D, Shailendra R, Maheshwari R, Juyal A. A comparative study of pedicle screw fixation in dorsolumbar spine by freehand versus image-assisted technique: a cadaveric study. Indian J Orthop. 2016;50(3):243249.

4. Lee C-H, Hyun S-J, Kim YJ, Kim K-J, Jahng T-A, Kim H-J. Accuracy of free hand pedicle screw installation in the thoracic and lumbar spine by a young surgeon: an analysis of the first consecutive 306 screws using computed tomography. Asian Spine J. 2014;8(3):237-243.

5. Oshina M, Horii C, Hirai S, et al. Comparison of freehand sagittal trajectories for inserting pedicle screws between $\mathrm{C} 7$ and T5. Clin Spine Surg. 2018 Aug; 31(7): E357-E362.

6. Al-Khouja L, Shweikeh F, Pashman R, Johnson JP, Kim TT, Drazin D. Economics of image guidance and navigation in spine surgery. Surg Neurol Int. 2015;6(suppl 10):S323-S326. doi:10.4103/2152-7806.159381

7. Parker SL, McGirt MJ, Farber SH, et al. Accuracy of freehand pedicle screws in the thoracic and lumbar spine: analysis of 6816 consecutive screws. Neurosurgery. 2011;68(1):170-178.

8. Rivkin MA, Okun JF, Yocom SS. Novel free-hand T1 pedicle screw method: review of 44 consecutive cases. J Neurosci Rural Pract. 2014;5(4):349-354.

9. Stanescu S, Ebraheim NA, Yeasting R, et al. Morphometric evaluation of the cervico-thoracic junction. Practical considerations for posterior fixation of the spine. Spine (Phila Pa 1976). 1994;19(18):2082-2088.

10. Yan J, Li K, Zheng Y, et al. The ipsilateral adjacent laminae: a reliable guide in determining the direction of subaxial cervical pedicle axis in the sagittal plane. Spine (Phila Pa 1976). 2015;40(21):1647-1652.

11. Li J, Zhao H, Xie H, et al A new free-hand pedicle screw placement technique with reference to the supraspinal ligament. J Biomed Res. 2014;28(1):64-70.

12. Fennell VS, Palejwala S, Skoch J, et al. Freehand thoracic pedicle screw technique using a uniform entry point and sagittal trajectory for all levels: preliminary clinical experience. J Neurosurg Spine. 2014;21(2):778-784.

13. Pal D, Bayley E, Magaji SA, Boszczyk BM. Freehand determination of the trajectory angle for cervical lateral mass screws: how accurate is it? Eur Spine J. 2011;20(6):972-976.

14. Xu Z-X, Chen Y, Kuai S-G. The human visual system estimates angle features in an internal reference frame: a computational and psychophysical study. $J$ Vision. 2018;18(13):1-11.

15. Elfiky T, Patil ND, Samartzis D, Luk KD. The concept of lamina-pedicle perpendicularity: part 1, the lumbar spine. Asian Spine J. [published online ahead of print, 2020 Feb 14]. Asian Spine J. 2020;10.31616/asj. 2019.0114

16. Elfiky T, Patil ND, Samartzis D, Luk KD. The concept of lamina-pedicle perpendicularity: part 2, the dorsal spine. Asian Spine J. [published online ahead of print, 2020 Jun 12]. Asian Spine J. 2020;10.31616/asj.2019.0334.

17. Patil ND, Patel HB, Hussain N, Saidane K. Cemented hemiarthroplasty of the hip in a patient with ipsilateral knee arthrodesis: surgical difficulties and techniques. J Orthop Case Rep. 2018;8(1):75-79.

18. Kim KD, Johnson JP, Bloch BS, et al. Computerassisted thoracic pedicle screw placement: an in vitro feasibility study. Spine. 2001;26(4):360-364.

19. Stauber MH, Bassett GS Pedicle screw placement with intraosseous endoscopy. Spine. 1994;19(1):57-61.

20. Laine T, Lund T, Ylikoski M, Lohikoski J, Schlenzka D. Accuracy of pedicle screw insertion with and without computer assistance: a randomised controlled clinical study in 100 consecutive patients. Eur Spine J. 2000;9(3):235-224.

21. Rajasekaran S, Vidyadhara S, Ramesh P, Shetty AP. Randomized clinical study to compare the accuracy of navigated and non-navigated thoracic pedicle screws in deformity correction surgeries. Spine. 2007;32(2):E56-E64.

22. Rampersaud YR, Foley KT, Shen AC, Williams S, Solomito M. Radiation exposure to the spine surgeon during fluoroscopically assisted pedicle screw insertion. Spine (Phila Pa 1976). 2000;25(20):2637-2645.

23. Ul Haque M, Shufflebarger HL, O’Brien M, Macagno A. Radiation exposure during pedicle screw placement in adolescent idiopathic scoliosis: is fluoroscopy safe? Spine (Phila Pa 1976). 2006;31(21):2516-2520.

24. Allam Y, Silbermann J, Riese F, Greiner-Perth R. Computer tomography assessment of pedicle screw placement in thoracic spine: comparison between free hand and a generic 3D-based navigation techniques. Eur Spine J. 2013;22(3):648653. doi:10.1007/s00586-012-2505-7

25. Chung KJ, Suh SW, Desai S, Song HR. Ideal entry point for the thoracic pedicle screw during the free hand technique. Int Orthop. 2007;32(5):657-662. doi:10.1007/ s00264-007-0363-4

26. Goda Y, Higashino K, Toki S, et al. The pullout strength of pedicle screws following redirection after lateral wall breach 
or end-plate breach. Spine (Phila Pa 1976). 2016;41(15):12181223. doi:10.1097/BRS.0000000000001600

Disclosures and COI: The authors received no funding for this study and report no conflicts of interest.

Corresponding Author: Nirmal D. Patil, Spinal Fellow, Department of Spine surgery,
Queens Medical Centre, Nottingham, UK; Email: nirmalpatil2008@gmail.com.

Published 11 November 2020

This manuscript is generously published free of charge by ISASS, the International Society for the Advancement of Spine Surgery. Copyright (C) 2020 ISASS. To see more or order reprints or permissions, see http://ijssurgery.com. 